\title{
A STUDY OF IT STUDENTS' ATTITUDE TOWARDS LEARNING ENGLISH- ANALYZING THE CAUSES TO MARCH TOWARDS A NEED BASED CURRICULUM
}

\author{
Dr. Jagdish Joshi \\ Dr. Dilber Gulestan (Mehta)
}

\begin{abstract}
:
English today is a window to the world, a link language and also a cutting edge initiative to be well placed in one's career. In some of the advanced and professional courses, English is included as a part of Curriculum (ESP) In spite of the inclusion of English as a subject, it is found that students are not able to master the language skills according to the demands of Industry. Due to this reason the placement ratio is very low. The reasons for not attaining the desired skills may vary and it may be Student Centric or Academic Centric.

This research paper tries to map the attitude of IT students towards learning English and tries to analyze the reasons of students ' like and dislike for English further aiming to frame a Need Based syllabus taking into consideration their responses and brightening their journey with better placements.
\end{abstract}

Key Words: Attitude of IT Students, ESP Reasons, Language Needs, Need Analysis.

\section{Introduction:}

What matters at the end of the journey is the placement percentage of an Institute. Yes the decisions regarding the future of the Course/Degree are made on how successful its past students were .There is a great shift in the recruiting and placement patterns than before. Today testing is not limited to the domain knowledge of a student but it has extended its parameters to Soft-Skills. Hard skills can get you an interview but not a job. Keeping this in mind many Professional Courses have imbibed soft-skills in their curriculum. Only then the students will be able to march ahead in the race.

This paper maps the attitude of students towards learning English in a Professional Course of Information Technology. The students in this course have a graded syllabus from first to third semester where they study English for a Specific Purpose (ESP).The students have come after 
clearing HSC from different mediums and varied schools where they have learnt English as one of the subjects for ten to twelve years. Here in the M.Sc.IT course, they have studied English in three semesters as the following subjects. Communication Skills in English (First Semester) Business Communication Skills (Second Semester) Soft-Skills (Third Semester) After studying three language subjects as theory and practical, there is a shift in their attitude, ideas towards the subject. Their responses also helps to address the researcher to trace the causes, gaps and difficulties of students and will assist towards betterment in reframing a better need based syllabus and strengthen the teaching strategy for better results.

\section{OBJECTIVES OF THE STUDY:}

-To know the attitude of students towards the Subject.

-To find out the factors those contribute to the Lack of Learning.

-To know about the views of students pertaining their difficulty in Learning and bring

changes in the syllabus and teaching pattern accordingly.

\section{Sampling Plan:}

The questionnaire designed has been collected from B.Sc.IT Students who have completed their third semester. The information was collected from 100 students. The questionnaire was designed to identify the most preferred attributes in students towards learning the subject. The questionnaire has two sections. The first section addresses the primary details of the respondents, the second section looks for the information about various reasons for the their likes and dislikes and their attitude.

\section{Data Collection Method:}

Primary data has been collected for the help of research from the students of B.Sc IT 3rd Semester using a structured questionnaire as an instrument of research.

\section{Data Scaling and Measurement:}

In order to increase the accuracy of research work,qualitative data scaling techniques such as nominal scale and ordinal scale were used as per requirement. With a view to generating valid and precise information, data was measured through technique like Likert 
Type scale.

\section{Data Analysis:}

Data was analysed with the help of tables.For this survey factor- analysis was conducted to determine the most important factors influencing teachers attitude towards using technology in ELT.For that ,the KMO-Bartlett's test was applied.The statistical Package for Social Sciences(SPSS)was used to do the analysis.

\section{Factor Analysis:}

Factor -Analysis is a very widely used technique in research for reducing data complexity by reducing the number of attributes being studied. Usually one finds a decision maker wondering what exactly affects the non-use of technology in ELT.

The number of affecting criteria could range from just one or two to fifteen or twenty and often one shoots in the dark to figure out what really drives the attitudes of teachers. Factor analysis is a good way of resolving this confusion and identifying latent factors from an array of seemingly important attributes. In a more general way, factor analysis is a set of techniques which by analyzing correlations between attributes, reduces their number into fewer factors which explain much of the original data more economically Even though a subjective interpretation can result from a factor analysis output, the procedure often provides an insight into relevant psychometric attributes, and results in economical use of data collection efforts.

In the present research a questionnaire was designed and the respondents' were asked to rank the attributes listed in section two of the questionnaire. There were no restrictions on the ranking system; the respondents were allowed to award any rank from 1to 5 for a particular attribute. The respondents have given their responses on 5 point scale ranging from 1 (strongly agree] to 5 [strongly disagree.]

The adequacy of data is evaluated on the basis of Kaiser-Meyer-Olkin [KMO] measures of sampling adequacy and Bartlett's test of sphericty 
Towards Excellence: An Indexed, Refereed \& Peer Reviewed Journal of Higher Education / Dr. Jagdish Joshi \& Dr. Dilber Gulestan/ Page 490-506

\begin{tabular}{|c|c|c|}
\hline \multicolumn{3}{|c|}{ KMO and Bartlett's Test } \\
\hline \multirow{2}{*}{ Kaiser-Meyer-Olkin Measure of Sampling Adequacy. } & .667 \\
\hline \multirow{3}{*}{ Bartlett's Test of Sphericity } & Approx. Chi-Square & 1204.796 \\
\cline { 2 - 3 } & Df & 496 \\
\cline { 2 - 3 } & Sig. & .000 \\
\hline
\end{tabular}

The KMO measure of sampling adequacy is 0.667 , indicating that the present data are Suitable for factor analysis. Similarly, Bartlett's test of sphericity is a significant $[\mathrm{P}<0.001]$, indicating sufficient correlation exists between the variables to proceed with the analysis. 
Towards Excellence: An Indexed, Refereed \& Peer Reviewed Journal of Higher Education / Dr. Jagdish Joshi \& Dr. Dilber Gulestan/ Page 490-506

\begin{tabular}{|c|c|c|}
\hline Communalities & Initial & Extraction \\
\hline $\begin{array}{l}\text { Only Technical subjects are important, so students } \\
\text { have a poor mindset for learning English }\end{array}$ & 1.000 & .585 \\
\hline Fear of Speaking English & 1.000 & .765 \\
\hline $\begin{array}{l}\text { Difficulty of Learning English because of Poor } \\
\text { Base in school }\end{array}$ & 1.000 & .649 \\
\hline Hesitate to Speak because of lack of confidence & 1.000 & .760 \\
\hline $\begin{array}{l}\text { Medium of instruction in school was Gujarati and } \\
\text { therefore lack of exposure }\end{array}$ & 1.000 & .799 \\
\hline Lack of vocabulary to express yourself & 1.000 & .773 \\
\hline Bad Experience in the past & 1.000 & .592 \\
\hline $\begin{array}{l}\text { Unaware about the importance and use of language } \\
\text { in IT/Corporate }\end{array}$ & 1.000 & .680 \\
\hline Negative thinking for learning & 1.000 & .610 \\
\hline Not habituated To speak English & 1.000 & .755 \\
\hline Have a dislike for the subject & 1.000 & .652 \\
\hline $\begin{array}{l}\text { Students believe that Language Skills can be } \\
\text { acquired later }\end{array}$ & 1.000 & .699 \\
\hline $\begin{array}{l}\text { Students believe that good job can be secured } \\
\text { without language skills }\end{array}$ & 1.000 & .609 \\
\hline $\begin{array}{l}\text { Students are not able to speak because they use } \\
\text { Grammar Translation Method. }\end{array}$ & 1.000 & .602 \\
\hline Students don't use Structural Approach & 1.000 & .566 \\
\hline Feel embarrassed in front of the audience & 1.000 & .740 \\
\hline Hesitate to speak due to Poor Pronunciation & 1.000 & .661 \\
\hline $\begin{array}{l}\text { Self-Satisfaction level for improvement of } \\
\text { language skills is low }\end{array}$ & 1.000 & .638 \\
\hline Less exposure to listening so Lack listening skills & 1.000 & .747 \\
\hline Lack of reading skills & 1.000 & .709 \\
\hline Lack of writing skills & 1.000 & .694 \\
\hline $\begin{array}{l}\text { Lack of Reinforcement from the teacher./ Nature of } \\
\text { the Language teacher matters }\end{array}$ & 1.000 & .653 \\
\hline $\begin{array}{l}\text { Random grouping in Language learning activities } \\
\text { prove fruitful }\end{array}$ & 1.000 & .686 \\
\hline
\end{tabular}


Towards Excellence: An Indexed, Refereed \& Peer Reviewed Journal of Higher Education / Dr. Jagdish Joshi \& Dr. Dilber Gulestan/ Page 490-506

\begin{tabular}{|l|c|c|}
\hline $\begin{array}{l}\text { Marks oriented and compulsiveness in learning } \\
\text { language leads to better efforts }\end{array}$ & 1.000 & .647 \\
\hline $\begin{array}{l}\text { The current language Syllabus is in accordance } \\
\text { with the Industry demand }\end{array}$ & 1.000 & .728 \\
\hline $\begin{array}{l}\text { Practical Exam of Language skills should be } \\
\text { conducted./ Practical sessions of GD, Presentation } \\
\text { Skills helps to enhance your skills }\end{array}$ & 1.000 & .681 \\
\hline $\begin{array}{l}\text { Industrial Visits are required for better real world } \\
\text { knowledge of tasks }\end{array}$ & 1.000 & .691 \\
\hline $\begin{array}{l}\text { Besides regular classes at the institute ,Students do } \\
\text { not devote extra time and efforts to enhance } \\
\text { language skills }\end{array}$ & 1.000 & .405 \\
\hline Peer-group motivates you to learn language better & 1.000 & .704 \\
\hline Language Learning makes you more confident & 1.000 & .671 \\
\hline $\begin{array}{l}\text { There is a wide gap between English language } \\
\text { learnt at school level and UG Level }\end{array}$ & 1.000 & .669 \\
\hline $\begin{array}{l}\text { Use of Language Lab will make your learning } \\
\text { more interesting. }\end{array}$ & 1.000 & .547 \\
\hline Extraction Method: Principal Component Analysis. & & \\
\hline
\end{tabular}

Out of 32 Communalities, all variables are acceptable and fit for the factor solution as their extraction values are greater than 0.4 (Table )

The first 10 factors are as follows: 
Towards Excellence: An Indexed, Refereed \& Peer Reviewed Journal of Higher Education / Dr. Jagdish Joshi \& Dr. Dilber Gulestan/ Page 490-506

\begin{tabular}{|c|c|c|c|c|c|c|c|c|c|}
\hline \multicolumn{10}{|c|}{ Total Variance Explained } \\
\hline \multirow[b]{2}{*}{ Component } & \multicolumn{3}{|c|}{ Initial Eigenvalues } & \multicolumn{3}{|c|}{$\begin{array}{l}\text { Extraction Sums of } \\
\text { Squared Loadings }\end{array}$} & \multicolumn{3}{|c|}{$\begin{array}{c}\text { Rotation Sums of Squared } \\
\text { Loadings }\end{array}$} \\
\hline & Total & $\begin{array}{c}\% \text { of } \\
\text { Variance } \\
\end{array}$ & $\begin{array}{c}\text { Cumulative } \\
\%\end{array}$ & Total & $\begin{array}{c}\% \text { of } \\
\text { Variance }\end{array}$ & $\begin{array}{c}\text { Cumulative } \\
\%\end{array}$ & Total & $\begin{array}{c}\% \text { of } \\
\text { Variance } \\
\end{array}$ & $\begin{array}{c}\text { Cumulative } \\
\%\end{array}$ \\
\hline 1 & 5.749 & 17.966 & 17.966 & 5.749 & 17.966 & 17.966 & 3.065 & 9.577 & 9.577 \\
\hline 2 & 3.592 & 11.225 & 29.192 & 3.592 & 11.225 & 29.192 & 2.658 & 8.306 & 17.883 \\
\hline 3 & 2.700 & 8.438 & 37.630 & 2.700 & 8.438 & 37.630 & 2.486 & 7.767 & 25.650 \\
\hline 4 & 1.757 & 5.489 & 43.119 & 1.757 & 5.489 & 43.119 & 2.414 & 7.543 & 33.193 \\
\hline 5 & 1.529 & 4.777 & 47.895 & 1.529 & 4.777 & 47.895 & 2.337 & 7.304 & 40.497 \\
\hline 6 & 1.416 & 4.426 & 52.322 & 1.416 & 4.426 & 52.322 & 1.870 & 5.842 & 46.340 \\
\hline 7 & 1.319 & 4.122 & 56.444 & 1.319 & 4.122 & 56.444 & 1.782 & 5.569 & 51.908 \\
\hline 8 & 1.167 & 3.645 & 60.089 & 1.167 & 3.645 & 60.089 & 1.772 & 5.538 & 57.447 \\
\hline 9 & 1.122 & 3.507 & 63.596 & 1.122 & 3.507 & 63.596 & 1.499 & 4.686 & 62.132 \\
\hline 10 & 1.019 & 3.184 & 66.780 & 1.019 & 3.184 & 66.780 & 1.487 & 4.648 & 66.780 \\
\hline 11 & .945 & 2.953 & 69.734 & & & & & & \\
\hline 12 & .864 & 2.700 & 72.434 & & & & & & \\
\hline 13 & .816 & 2.551 & 74.985 & & & & & & \\
\hline 14 & .814 & 2.543 & 77.528 & & & & & & \\
\hline 15 & .704 & 2.201 & 79.729 & & & & & & \\
\hline 16 & .659 & 2.059 & 81.788 & & & & & & \\
\hline 17 & .657 & 2.053 & 83.841 & & & & & & \\
\hline 18 & .634 & 1.981 & 85.822 & & & & & & \\
\hline 19 & .563 & 1.761 & 87.583 & & & & & & \\
\hline 20 & .508 & 1.586 & 89.169 & & & & & & \\
\hline 21 & .442 & 1.382 & 90.551 & & & & & & \\
\hline 22 & .436 & 1.361 & 91.912 & & & & & & \\
\hline 23 & .398 & 1.243 & 93.154 & & & & & & \\
\hline 24 & .332 & 1.039 & 94.193 & & & & & & \\
\hline 25 & .298 & .932 & 95.125 & & & & & & \\
\hline 26 & .288 & .899 & 96.024 & & & & & & \\
\hline 27 & .274 & .856 & 96.880 & & & & & & \\
\hline 28 & .261 & .816 & 97.696 & & & & & & \\
\hline
\end{tabular}


Towards Excellence: An Indexed, Refereed \& Peer Reviewed Journal of Higher Education / Dr. Jagdish Joshi \& Dr. Dilber Gulestan/ Page 490-506

\begin{tabular}{|l|r|r|r|l|l|l|l|l|}
\hline 29 & .247 & .770 & 98.467 & & & & & \\
\hline 30 & .208 & .650 & 99.117 & & & & & \\
\hline 31 & .180 & .564 & 99.681 & & & & & \\
\hline 32 & .102 & .319 & 100.000 & & & & & \\
\hline
\end{tabular}

The total variance explained by principal components is displayed in table-3. It indicates that there is a significant drop in the Eigen values from the tenth component onwards. Hence, the first ten factors in the initial solution have Eigen values over 1 and they account for about $66.70 \%$ of the observed variation. According to Kaiser Criterion, only the first ten factors should be used because Eigen values are all less than 1.The first 10 factors are as follows:

Only Technical subjects are important, so students have a poor mindset for learning English Fear of Speaking English

Difficulty of Learning English because of Poor Base in school

Hesitate to Speak because of lack of confidence

Medium of instruction in school was Gujarati and therefore lack of exposure

Lack of vocabulary to express yourself

Bad Experience in the past

Unaware about the importance and use of language in IT/Corporate

Negative thinking for learning

Not habituated To speak English 
Towards Excellence: An Indexed, Refereed \& Peer Reviewed Journal of Higher Education / Dr. Jagdish Joshi \& Dr. Dilber Gulestan/ Page 490-506

\begin{tabular}{|c|c|c|c|c|c|c|c|c|c|c|}
\hline \multicolumn{11}{|c|}{ Rotated Component Matrix ${ }^{a}$} \\
\hline & \multicolumn{10}{|c|}{ Component } \\
\hline & 1 & 2 & 3 & 4 & 5 & 6 & 7 & 8 & 9 & 10 \\
\hline $\begin{array}{l}\text { Students believe } \\
\text { that Language } \\
\text { Skills can be } \\
\text { acquired later } \\
\end{array}$ & 789 & & & & & & & & & \\
\hline $\begin{array}{l}\text { Unaware about } \\
\text { the importance } \\
\text { and use of } \\
\text { language in } \\
\text { IT/Corporate }\end{array}$ & .709 & & & & & & & & & \\
\hline $\begin{array}{l}\text { Self-Satisfaction } \\
\text { level for } \\
\text { improvement of } \\
\text { language skills is } \\
\text { low }\end{array}$ & .541 & & & & & & & & & \\
\hline $\begin{array}{l}\text { Negative thinking } \\
\text { for learning }\end{array}$ & .526 & & & & & & & & & \\
\hline $\begin{array}{l}\text { Hesitate to speak } \\
\text { due to Poor } \\
\text { Pronunciation } \\
\end{array}$ & & & & & & & & & & \\
\hline $\begin{array}{l}\text { Only Technical } \\
\text { subjects are } \\
\text { important, so } \\
\text { students have a } \\
\text { poor mindset for } \\
\text { learning English }\end{array}$ & & & & & & & & & & \\
\hline $\begin{array}{l}\text { Hesitate to Speak } \\
\text { because of lack of } \\
\text { confidence }\end{array}$ & & .844 & & & & & & & & \\
\hline \begin{tabular}{|l|} 
Fear of Speaking \\
English \\
\end{tabular} & & .816 & & & & & & & & \\
\hline $\begin{array}{l}\text { Feel embarrassed } \\
\text { in front of the } \\
\text { audience }\end{array}$ & & .657 & & & & & & & & \\
\hline $\begin{array}{l}\text { Language } \\
\text { Learning makes } \\
\text { you more } \\
\text { confident }\end{array}$ & & & .751 & & & & & & & \\
\hline
\end{tabular}


Towards Excellence: An Indexed, Refereed \& Peer Reviewed Journal of Higher Education / Dr. Jagdish Joshi \& Dr. Dilber Gulestan/ Page 490-506

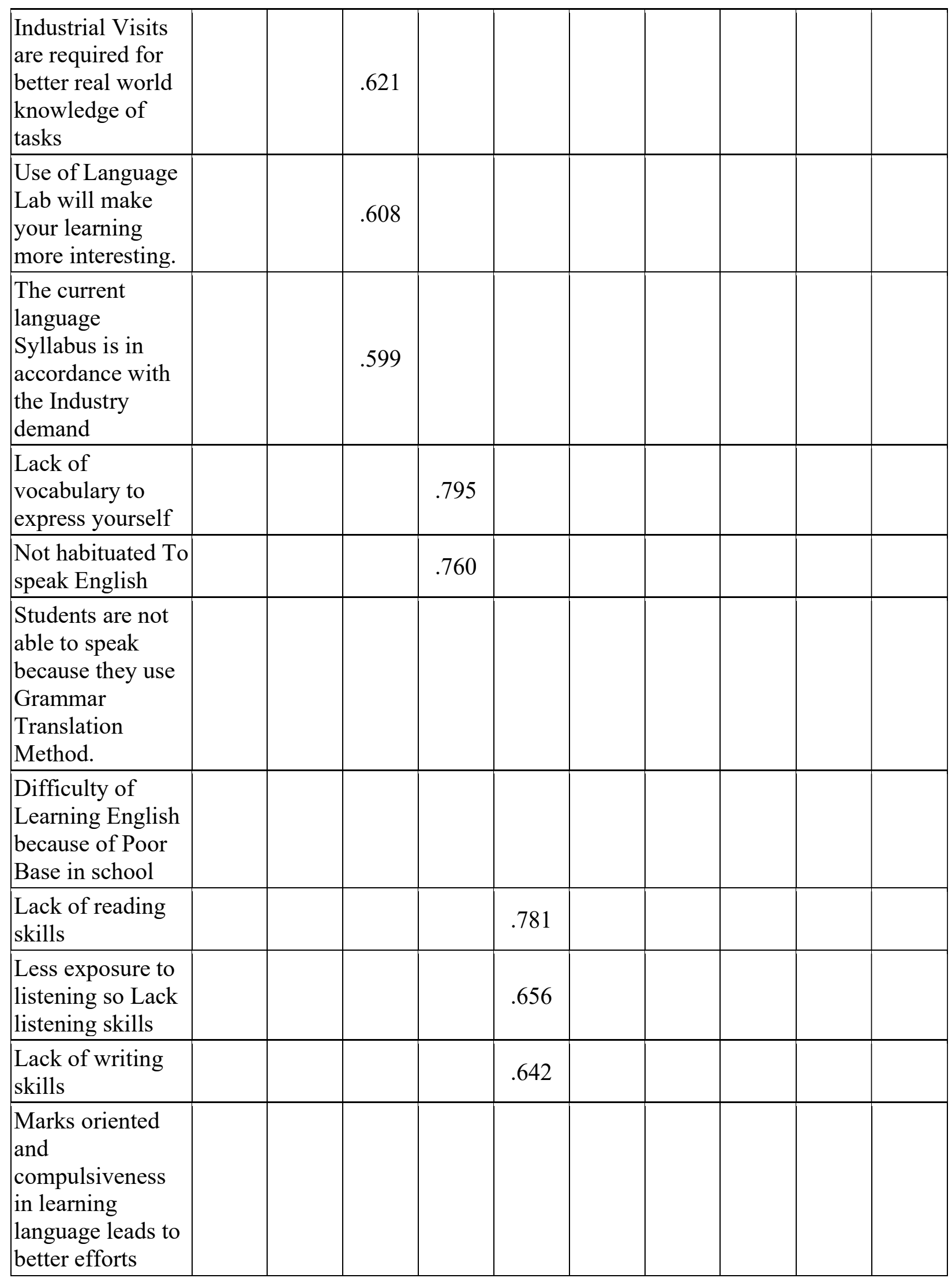


Towards Excellence: An Indexed, Refereed \& Peer Reviewed Journal of Higher Education / Dr. Jagdish Joshi \& Dr. Dilber Gulestan/ Page 490-506

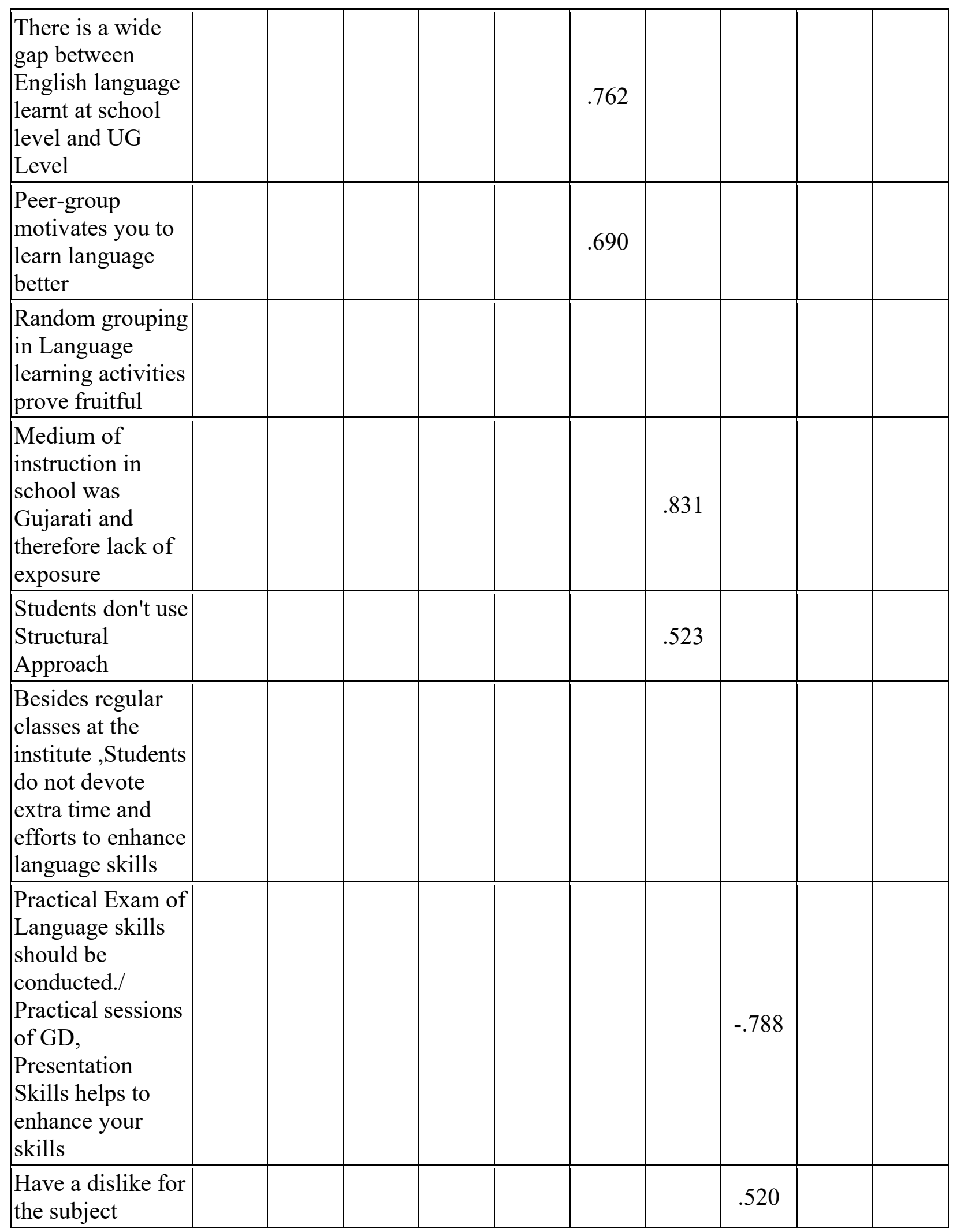




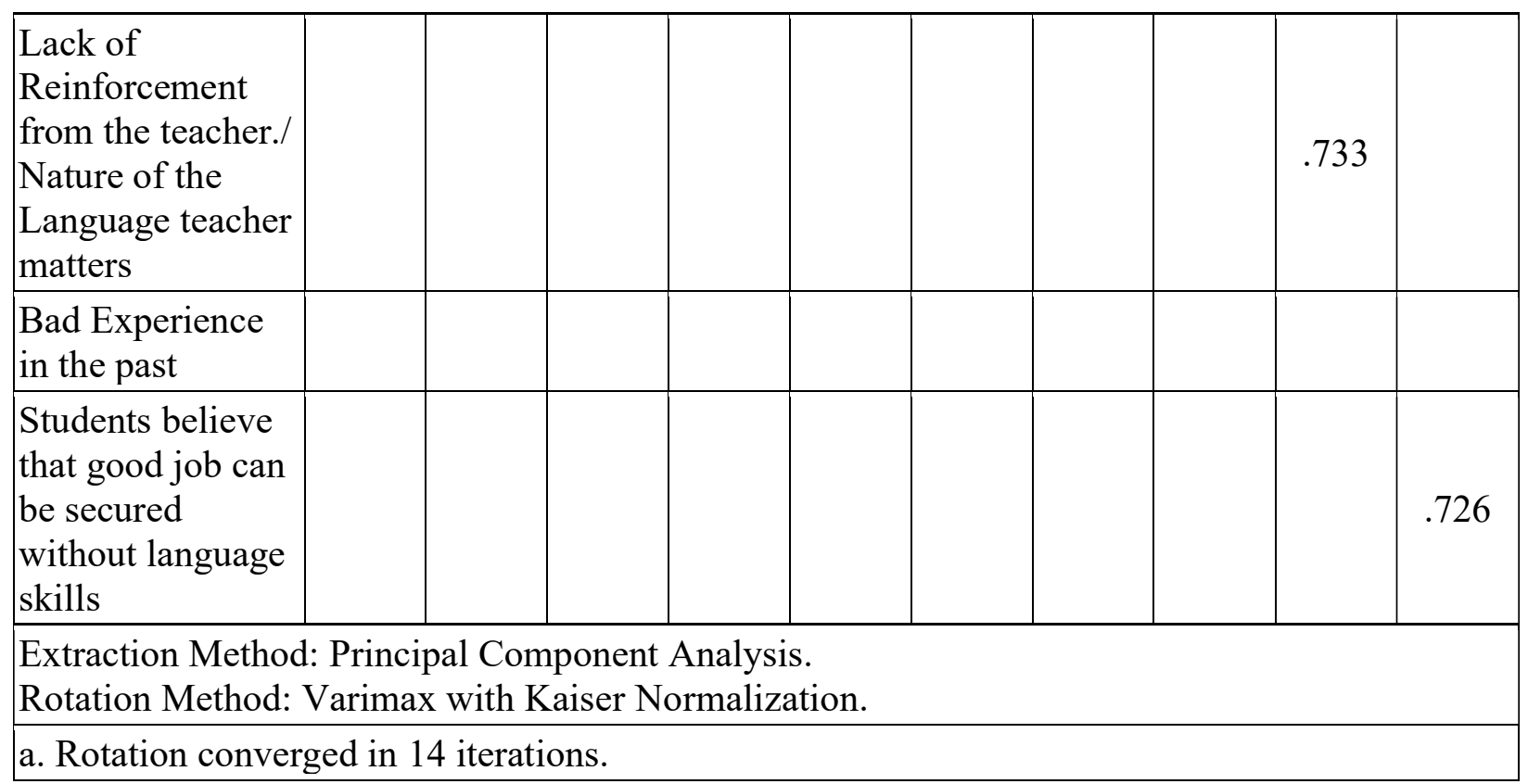

Table-4 presents the rotated component matrix. Here one can observe how the extracted factors are related to the original variables. The factors are rotated with the use of Varimax with Kaiser Normalization rotation method. We use principal component analysis [PCA] method for factor extraction. We have used only those factors which have Loading value is greater than 0.5 for interpretation purpose.

\section{Interpretation:}

Factor 1. Contributed to variations in students' attitude about learning the language and it consists the following attributes:

1. Students believe that language skills can be acquired later.

2. Students are not much aware about the language use in Corporate.

3. Self-Satisfaction level of the students is low.

4. Negative thinking towards acquiring/learning a language

These 4 attributes have loading as $0.789,0,709,0,541,0,526$ respectively. From these 4 attributes it can be interpreted that it is due to the gap on the students' side and their beliefs about learning language that makes them less interested. Their belief that language /soft-skills can be acquired 
later prolongs their learning and acts as a barrier in the present situation. They have a very casual attitude towards mastering the skills at present.

The next attribute points to their awareness about the use of language in corporate which means they do not have an exact idea of the language functionalities in the day to day corporate life.

The 3rd and the 4th attributes are personal and psychological in nature and reflect a denial and lack of interest towards learning. When the satisfaction level of the student is low they cannot master of polish the language and moreover negative thinking hinders their effort to acquire the skills.

So here in Factor 1. Major weaknesses' lie on the part of students which need to be corrected until they reach their goals.

\section{Factor 2:}

This factor includes 3 attributes on the part of students and the attributes collectively reflect a kind of fear which makes the students hesitant to use language effectively. The 3 attributes covered under this factor are as follows:

1. Hesitate to speak because of lack of Confidence

2. Fear of speaking English

3. Feel embarrassed in front of the audience.

Here the 3rd attribute is the result of the first two .These attributes are mainly the result of fear, shyness and lack of confidence which makes them uncomfortable to use English language in public.

\section{Factor 3:}

Factor 3 contains 4 attributes which are a suggestive in nature. These attributes are as follows:

1. Language Learning makes you more Confident. 
2.Industrial visits are required for better real world knowledge of tasks.

3.Use of language Lab and Language Software will make learning more interesting

4. The Current syllabus is in accordance with the Industry demands

The above mentioned attributes drive home the point that students clearly have an idea that Language learning will make them more confident. They are in need of more Industrial exposure to get real world knowledge of daily tasks and they believe that Online learning of language will be more effective. If all this is incorporated in teaching language it will bring a difference.

\section{Factor 4:}

Two attributes belong to this factor. Both are on the part of students.

1. Lack of vocabulary to express oneself

2. Not habituated to speak English

So here the attributes state that students have poor vocabulary to express themselves and when words fall short they are unable to speak. The next attribute is they do not use English often and this makes them hesitant when required to do so. More emphasis has to be laid to strengthen vocabulary and English must be used habitually.

\section{Factor 5:}

Three attributes are covered under factor 5.The loading is as 0,781, 0.656 and 0,642 respectively. The factors are as under.

\section{Lack of Reading Skills}

2. Less exposure to listening so lack of speaking skills.

3. Lack of writing skills.

The above factors show that the students are not well versed to 4 language skills and so not able to use language effectively.

\section{Factor 6:}


Two attributes are covered under this factor.Their loading is as 0.762 and 0.690 respectively .These factors are:

1. There is a wide gap between English language learnt at school and at UG Level.

2. Peer group helps you to use language better.

The first attribute signals at the difference in the syllabus at school at UG Level. In schools more emphasis is on Prose, Poetry, grammar and cramming of question answers whereas here in UG skills are to be mastered and language has to be used in real world scenario.

Secondly the students agree that their friends and team mates help them to learn and use language better so if teaching is done in accordance it will be more effective.

\section{Factor 7:}

It includes 2 attributes. The medium of instruction of most of the students in school was Gujarati and therefore they lack exposure and secondly they do not use Structural approach which means teaching and learning in English. The Grammar Translation method which is widely adapted in school weakens the thought process and vocabulary in English.

\section{Conclusion:}

The above analysis has drawn various inferences. The varied attitude of students marked in the questionnaire if taken into consideration then it will help to design a more focused syllabus and also bring improvement in the teaching methodology. Out of the 32 questions the major attributes that have come out of the analysis from the students' side drive home the point that the wrong notion that language can be mastered later needs to be corrected. If language is mastered during the Study period then it will help them towards better placements. The other attributes include fear, shyness, lack of confidence, lack of vocabulary, lack of practice to speak English. This can be improved from the students' side by using language effectively in routine communication, learning the functions of a language and that will gradually make them confident.

The other factors include poor base of English in school and a wide gap in language taught at schools and at UG Level. This gap needs to be bridged which can smoothen the way. The syllabus 
in schools, the teaching method needs a change. The use of grammar translation method must be replaced by Communicative approach and instead of learning the prose and poetry answers there must be more communicative and functional exercises which help them in practical life. This will help the students who have studied in Gujarati medium. The use of grammar translation method makes the student think in Guajarati and translate in English which lessens the English vocabulary. Thought process in English enriches the English vocabulary. A syllabus which allows students to use more practically keeping in mind Industry approach will be more suitable. The exact transactions and situations that are faced at Industry must be a part of syllabus. E.g. Dealing with customers, taking the requirement of customers for software development/web development, assigning tasks to the team, talking with the boss etc. This situations will figure out an exact picture of the real world they are doing to work with.

Finally the realization on the part of students' that Language cannot be mastered all of a sudden, it needs to be learned, cultivated and practiced in situations not in isolation is necessary. Moreover the Organizations need Industry ready Candidates not the ones to be polished by them. 


\title{
References
}

1.Luthra, Simran. Step Ahead with Soft Skills Oxford University Press, July, 2017.

2. Mulaik, Stanley. Foundations of Factor Analysis. Chapman \&Hall/CRC, 2009.

3. Konar N. Communication Skills for Professionals, Prentice Hall India Learning Private Limited; 2 edition, 2011.

4. Penny, UR. A Course in Language Teaching, Cambridge: Cambridge University Press, 1991.

5. Philippa Thomas, Debra Paul. The Human Touch: Personal skills for

Professional Success, BCS: The Chartered Institute for IT, 2012.

6. Richards, C Jack\& Rodgers S. Theodore. Approaches and Methods in English Language

Teaching, UK: Cambridge University Press, 2014.

7. Rutherfoord, Andrea J. Basic Communication Skills For Technology, 2nd Edition, Pearson. 2001.

\author{
Dr. Jagdish Joshi \\ Professor \& Director \\ UGC-HRDC \\ Gujarat University, Ahmedabad \\ E-Mail Id - joshijagdish@yahoo.com \\ \& \\ Dr. Dilber Gulestan (Mehta) \\ Assistant Professor \\ Department of ICT \\ VNSGU, Surat \\ E-Mail Id - degulestan@vnsgu.ac.in
}

